\title{
A GESTÃO DO CONHECIMENTO SOB O PONTO DE VISTA DE SUA COORDENAÇÃO: ESTRATÉGIA, TREINAMENTO E PLANEJAMENTO
}

\section{GESTIÓN DEL CONOCIMIENTO EM LA COORDINACIÓN SU PUNTO DE VISTA: ESTRATEGIA, CAPACITACIÓN Y PLANIFICACIÓN}

\author{
Tatiana Rossi* \\ Wanessa Caroline da Silva** \\ Marli Dias De Souza Pinto*** \\ Maria Bernardete Martins Alves ${ }^{* * * *}$ \\ Roberta Moraes de Bem ${ }^{* * * *}$
}

\begin{abstract}
RESUMO:
Introdução: Aborda a Gestão do Conhecimento em bibliotecas universitárias revelando um cenário envolvido com pessoas, tecnologias e processos e impõem preparo continuado dos gestores, bibliotecários e técnico-administrativos. Objetivo: Relatar a aplicação do Framework GC@BU, "Módulo Coordenação de Gestão do Conhecimento" (elemento Estratégia, Treinamento e capacitação e PDCA) na Biblioteca Universitária (BU) da Universidade Federal de Santa Catarina (UFSC). Metodologia: Utilizou-se a técnica de observação participante, uma vez que os pesquisadores analisaram a realidade social que os rodeia e, buscaram alinhar a estratégia da BU/UFSC às diretrizes da GC. Resultados: Verifica-se, que desafios ainda estão sendo impostos, mas percebem-se avanços significativos e a equipe de bibliotecários, começam a participar de treinamentos e capacitações, visando um trabalho qualitativo, voltado para a manutenção e criação de práticas de GC. Conclusão: Conclui-se apontando que houve melhoria na comunicação e na interação da equipe.
\end{abstract}

Palavras-chave: Gestão do conhecimento. Treinamento. Estratégia. PDCA. Framework GC@BU.

\footnotetext{
*Mestre em Ciência da Informação. E-mail: tatiana.rossi@ufsc.br

**Especialista em Gestão Pública. E-mail: wanessa.s@ufsc.br

***Doutora em Engenharia de Produção. Professora do Programa de Pós Graduação em Ciência da Informação - UFSC. E-mail: marli.dias@ufsc.br

****Bibliotecária da Biblioteca Central da Universidade Federal de Santa Catarina. E-mail: m.alves@ufsc.br

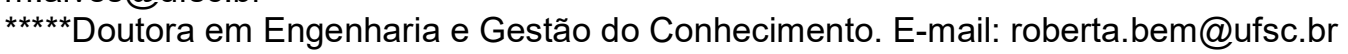




\section{INTRODUÇÃO}

As Bibliotecas Universitárias (BUs), como espaços de organização do conhecimento, estão diretamente ligadas às instituições de ensino superior. Seu público-alvo, constituído por pesquisadores, docentes, discentes e técnicoadministrativos, busca informações e conhecimentos para desenvolver o ensino, pesquisa, extensão de forma rápida e precisa.

As imposições advindas das novas técnicas, tecnologias e suportes representam, para as BUs, o desenvolvimento de serviços e produtos eficientes e com valor agregado de conhecimento, os quais visam, constantemente, as necessidades e demandas informacionais de seu público-alvo.

Os dirigentes das BUs precisam gerir suas unidades por meio da inovação e, neste contexto, a Gestão do Conhecimento (GC) tem favorecido a implementação de novas possibilidades, suprimindo as demandas do ambiente acadêmico com diferencial qualitativo (MARTINS, 2012). A GC impulsiona as Bus, no sentido de atender as constantes mudanças sobre a demanda dos usuários por serviços e produtos informacionais, entre outros aspectos.

Neste artigo, entende-se a GC como um processo que visa a criação, o armazenamento, a disseminação e a utilização do conhecimento, integrando pessoas, processos e tecnologias, alinhando estruturas com os objetivos fim.

$O$ processo de GC em organizações, como também nas bibliotecas universitárias, mostra-se como um cenário diretamente envolvido com pessoas, tecnologias e processos que requerem preparo continuado dos gestores, bibliotecários e demais técnico-administrativos destas unidades, cujo foco principal é o usuário no processo de criação do conhecimento. Desta maneira, precisam de capacitações e treinamentos para melhor se adaptar à realidade e ao uso das tecnologias (MIRANDA, 2010).

No contexto de BUs, a estratégia como elemento de tomada de decisão, torna-se fundamental, pois, possibilita saber quais recursos devem ser adquiridos e utilizados para que se possa tirar proveito das oportunidades e 
minimizar fatores que ameacem a consecução dos resultados desejados (MICHEL, 1976).

Em consonância com o paradigma centrado no usuário, as instituições necessitam de indicadores que possibilitem mostrar o que elas estão fazendo e quais os resultados de suas ações.

Costa e Ramalho (2010, p. 58) sinalizam que é:

imprescindível o estudo da satisfação dos usuários, considerando a sua implicação na relação entre as crescentes necessidades individuais e institucionais de informação e a oferta de estoques de informação, de modo não diferente, cada vez maiores e mais especializados.

O planejamento estratégico precisa ser formulado e estar estruturado na organização para que se possa estabelecer o rumo a ser seguido de forma integrada com toda a instituição.

A estratégia da organização precisa estar alinhada às diretrizes da GC e ser suficientemente clara para a equipe, de modo que todos entendam seu papel na organização e adotem o senso de comprometimento necessário para o sucesso de uma iniciativa de GC. Para tanto, a sensibilização e a formação do Staff precisa acompanhar essa necessidade de comprometimento que a GC requer; o treinamento e a capacitação são alicerces para a manutenção e a criação de práticas de GC que, por sua vez, devem ser administradas de forma a possibilitar a melhoria contínua, como propõe o PDCA.

O PDCA se constituí nas etapas: planejar, executar, checar e agir e é uma ferramenta gerencial que permite o controle eficaz dos processos de melhorias e padronizações de atividades, os quais propiciam transformações nas BUs, agregando mais conhecimento por meio do cumprimento das etapas.

Objetiva-se, no presente artigo, relatar a aplicação do Framework GC@BU, "Módulo Coordenação de Gestão do Conhecimento" (elemento Estratégia, Treinamento e capacitação e PDCA) na Biblioteca Universitária (BU) da Universidade Federal de Santa Catarina (UFSC).

A BU/UFSC, vinculada diretamente à reitoria da Instituição, possui uma centralização administrativa e técnica com dez bibliotecas, sendo uma central e 
nove setoriais, com a missão de promover a disseminação da informação e do conhecimento de forma participativa e articulada, visando o desenvolvimento das atividades de ensino, pesquisa, extensão e administração da UFSC (UNIVERSIDADE FEDERAL DE SANTA CATARINA, 2016a).

A justificativa de socialização deste relato de pesquisa centra-se no ano de 2015, quando a BU/UFSC implantou uma comissão de GC com o objetivo de melhorar o mapeamento e fluxo de informações e conhecimentos na Biblioteca (UNIVERSIDADE FEDERAL DE SANTA CATARINA, 2015). Os trabalhos da comissão são norteados pelo Framework GC@BU (BEM, 2015).

\section{GESTÃO DO CONHECIMENTO EM BIBLIOTECAS UNIVERSITÁRIAS}

O papel de geração de riqueza e poder nas organizações deixou de ser conquistado por fatores tradicionais como terra, trabalho e capital, para focar no conhecimento (CENTENARO; BONEMBERGER; LAIMER, 2016).

Sendo assim, a partir de uma metodologia empreendedora e cíclica, a fim de atingir objetivos, gerir estratégias organizacionais e criar diferenciais competitivos, o conhecimento e sua gestão passaram a ser o ativo principal da organização. Tudo isso, convertendo o conhecimento individual em conhecimento organizacional.

A GC pode ser definida como a coordenação sistemática de pessoas, tecnologias, processos e estrutura organizacional, a fim de agregar valor à organização por meio da reutilização de conhecimentos e da inovação. Essa coordenação é alcançada mediante a criação, compartilhamento e aplicação do conhecimento (DALKIR, 2011). Jain (2007) mostra que a GC trabalha com pessoas, instiga a originalidade, inovação, agilidade, adaptabilidade, compartilhamento de experiências e conhecimentos, inteligência e aprendizagem organizacional.

Diante de desafios e oportunidades, Danesghar e Parirokh (2012) conceituam as BUs como organizações de criação de conhecimento, nas quais grande quantidade de conhecimento é gerado regularmente para seus usuários 
e, também devido a isso, essas instituições necessitam de rápida evolução em virtude das exigências de seus serviços.

[...] as funções convencionais de uma biblioteca são coletar, processar, disseminar, armazenar e utilizar informação documental para proporcionar serviços para a sociedade. Na era da economia do conhecimento, a biblioteca se tornará a caça-dotesouro do conhecimento humano, participando na inovação do conhecimento, e tornando-se um importante elo na corrente da inovação (SHANHONG, 2000, p.1).

Contemporaneamente, o conhecimento é reconhecido como fator primordial em qualquer organização, as universidades com suas BUs são o locus da GC na comunidade acadêmica, repercutindo na sociedade.

Com isso, para a implantação da GC em BUs, Valentim (2013) sugere algumas iniciativas, tais como: mapeamento de fluxos formais e informais; desenvolvimento das competências essenciais; redes colaborativas; páginas amarelas; mapas conceituais; storytelling; e benchmarking.

A GC em BUs tem a responsabilidade de incrementar as competências do bibliotecário no gerenciamento de informação e de conhecimentos, a fim de dar destaques qualitativos aos serviços e produtos, projetados para $\mathrm{o}$ atendimento das diversas necessidades informacionais de seus atores.

Para responder as demandas impostas e agregar valor aos seus serviços, as BUs precisam criar formas inovadoras de gestão de recursos, infraestrutura e pessoas. Para tanto, não basta ao bibliotecário apenas o conhecimento técnico, é imprescindível que se torne um profissional com liderança para atender as novas demandas, singular e inovador, e que estabeleça uma relação com o usuário, ajustando-se às tecnologias, incorporando novas posições, passando assim, de mediador da informação a gestor do conhecimento.

\subsection{Estratégia de Gestão do Conhecimento}

A gestão do capital intelectual é prerrogativa para que as organizações apliquem suas estratégias por meio de seus diferenciais competitivos, com 
valor agregado de conhecimento, no desenvolvimento de seus produtos e serviços, ancorados por seus objetivos, missão e visão.

Mintzberg e Quinn (2001) sinalizam que uma estratégia bem formulada ajuda a ordenar e alocar os recursos de uma organização, com base em suas potencialidades, fragilidades, sendo uma maneira de ver a organização como um todo e de forma coerente.

São passos essenciais na definição da estratégia, a análise do meio, a identificação das oportunidades e ameaças, a análise interna da instituição para identificação de suas forças e fraquezas, embora o recurso dos valores e capacidades sejam mais valorizados a cada dia que passa (NICOLAU, 2005).

As BUs, como parte das universidades, refletem as turbulências sociais, econômicas, políticas e financeiras. As atividades de GC, direcionadas pela estratégia, buscam um melhor desempenho organizacional, desenvolvimento de produtos e serviços, qualidade, gestão de clientes, entre outros (CASTRO, 2005).

A estratégia de GC em uma organização requer envolvimento e comprometimento de todos, como requisito fundamental está a formação continuada e o treinamento da equipe, que são pontos essenciais nesse processo.

\subsection{Treinamento e Capacitação}

As tecnologias da informação e do conhecimento (TICs) ampliaram as formas de busca e recuperação da informação, alterando significativamente o tratamento, o armazenamento e o acesso à informação. Esse cenário impôs ao bibliotecário investimentos na sua capacidade de inovação, criatividade e habilidade para atender as necessidades e expectativas dos usuários, apoiando-os na busca, seleção e uso da informação. Neste contexto, no qual o usuário assume o papel relevante na sua competência em informação, a exigência do bibliotecário se amplia constantemente. (SANTOS, 2015). 
Uma reflexão sobre a necessidade de educação continuada, como parte integrante e indispensável da formação profissional do bibliotecário, é apontada no artigo de Medeiros (2006), quando menciona o surgimento da "information literacy", traduzido como "competência de informação", como uma questão fundamental para o aumento na demanda por programas de educação continuada.

No presente artigo, treinamento designa o processo de preparar pessoas para executar novas estratégias no âmbito da GC, ideia já postulada por Carvalho, Nascimento e Serafim (2012, p.169), para os quais, o treinamento é empregado com o mesmo significado que "aperfeiçoamento, capacitação, desenvolvimento e formação".

Parafraseando Carvalho, Nascimento e Serafim (2012), é por meio do treinamento que o bibliotecário avança no seu processo de ampliação de conhecimentos, habilidades, atitudes e experiências, vislumbrando novos cenários e ambientes, proporcionando aprendizagem e crescimento intelectual e profissional; aumentando as condições e possibilidades de autoconfiança e segurança no seu desempenho; constituindo uma experiência inovadora que impõe ações para atender as necessidades informacionais da instituição e de seus usuários.

O bibliotecário em seu papel social é mediador e facilitador das informações para os usuários e tem a capacidade de pensar, dialogar e interagir de forma interdisciplinar; dominar ferramentas de tecnologias de informação; conhecer o usuário; adaptar-se ao novo; ser flexível; ter comunicação oral e escrita fluida; ser capaz de aprender por si mesmo e de facilitar o aprendizado dos outros; e ter iniciativa. São saberes que se tornaram imprescindíveis ao exercício dessa profissão (SANTOS, 2015).

Cabe as instituições, as quais os bibliotecários estão vinculados, apoiálos e incentivá-los a participar de treinamentos com a possibilidade de oferecer um trabalho mais qualitativo, com ganhos relevantes de vantagem competitiva, tanto para eles quanto para a comunidade. 
A prática de aprendizado por intermédio de interação com outras pessoas traz benefícios para todos. $O$ treinamento possibilita a explicitação do conhecimento e seu compartilhamento, resultado de um processo dinâmico, por meio do qual o indivíduo assimila novos conhecimentos, habilidades e atitudes (RIBEIRO, 2006).

No âmbito da GC, a gestão por competência propõe, além de mapear as competências, identificar os gaps e as lacunas para eliminá-las ou minimizá-las (CARBONE et al., 2006).

Enfim, o treinamento de pessoas na BU é uma atividade contínua, constante e ininterrupta, ampliando o capital intelectual das pessoas, na busca da excelência para cumprir a missão, visão e objetivos institucionais.

\subsection{Planejamento, Desenvolvimento, Checagem E Ação (PDCA)}

Para que a GC promova mudanças eficientes, em um tempo adequado, é necessário que se tenham ferramentas/mecanismos de gestão que controlem, de forma eficiente, os processos e atividades. O Planejamento, Desenvolvimento, Checagem e Ação (PDCA) é uma ferramenta que tem como função auxiliar no diagnóstico, visando a padronização de informações, a melhoria contínua e a tomada de decisão. 


\section{Figura 1 - Ciclo PDCA}

\section{Ciclo PDCA}

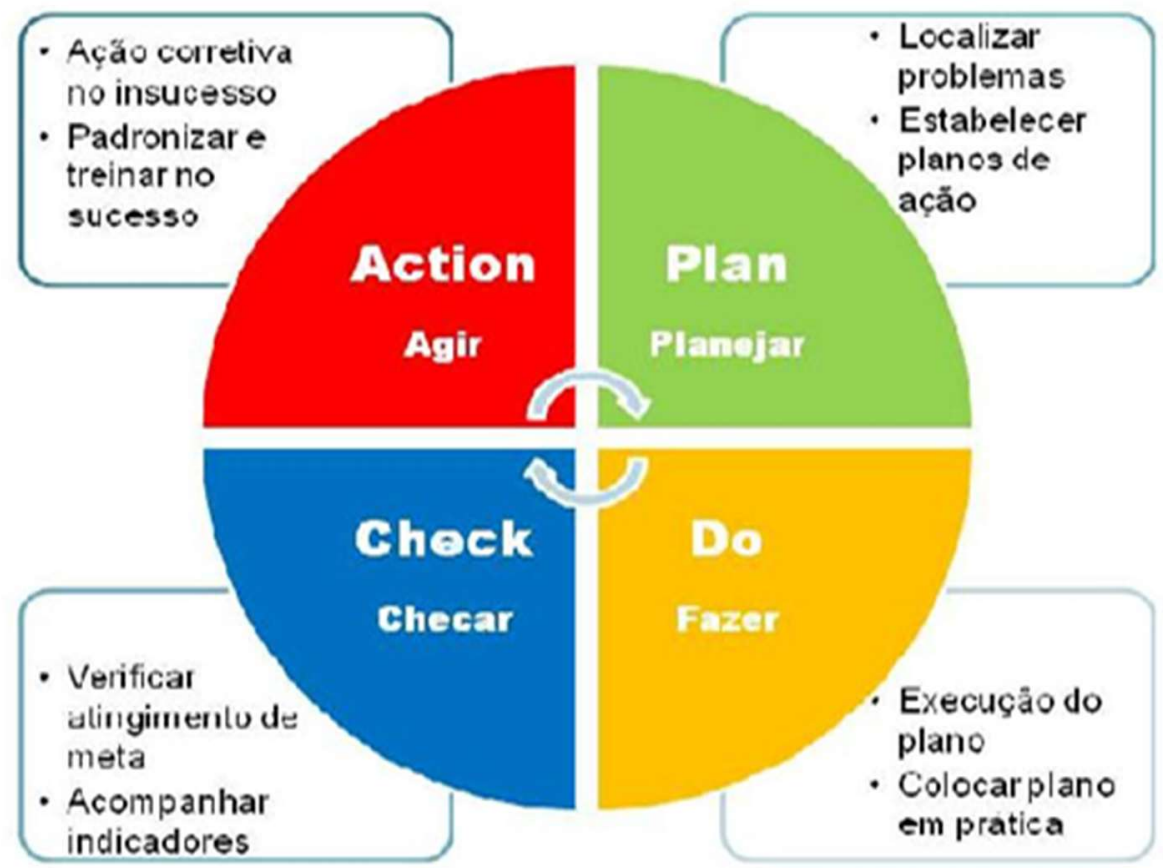

Fonte: Periard (2011)

Conforme demonstra a Figura 1, o Ciclo de PDCA tem como início e norte, o planejamento da ação, em seguida a execução do que foi planejado, verificação e conferência do processo e estabelecimento de ações a serem implementadas.

Após estas etapas, confronta-se as ações executas com o que foi planejado e corrige-se os pontos frágeis identificados durante o processo. É importante salientar que PDCA é cíclico e ininterrupto. (PERIARD, 2011).

Pacheco et al. (2005) associam o ciclo PDCA com a GC quando, após a checagem, ocorre o estudo dos resultados, focando na aprendizagem adquirida e apresentando uma nova etapa de planejamento e desenvolvimento, utilizando-se do novo conhecimento adquirido. Neste ciclo apontado pelo autor, promove-se o compartilhamento do conhecimento, no momento em que se realiza uma pausa e reflexões necessárias antes da retomada do ciclo. 


\section{$3 \quad$ FRAMEWORK GC@BU: MÓDULO COORDENAÇÃO DE GESTÃO DO CONHECIMENTO}

O Framework GC@BU é baseado na visão dos Sistemas Adaptativos Complexos e dividido em três grupos, denominados módulos: Coordenação de Gestão do Conhecimento; Recursos de Conhecimento; e Espaços de Aprendizagem/Conhecimento.

No Módulo "Coordenação de Gestão do Conhecimento", a ênfase se dá na forma de gestão pelos princípios de GC. A sua coordenação pode ser representada pela direção ou vice-direção da BU ou por uma comissão, que nesse caso, deve ter o acompanhamento da direção, tendo em vista que as atividades são intrínsecas à administração da BU.

Esse módulo possui quatro elementos (Figura 2): Pessoas, cultura e estrutura organizacional; Estratégia de Gestão do Conhecimento da organização; Treinamento e capacitação; e Planejamento, Desenvolvimento, Checagem e Ação (PDCA).

Figura 2 - Módulo Coordenação de Gestão do Conhecimento do Framework GC@BU

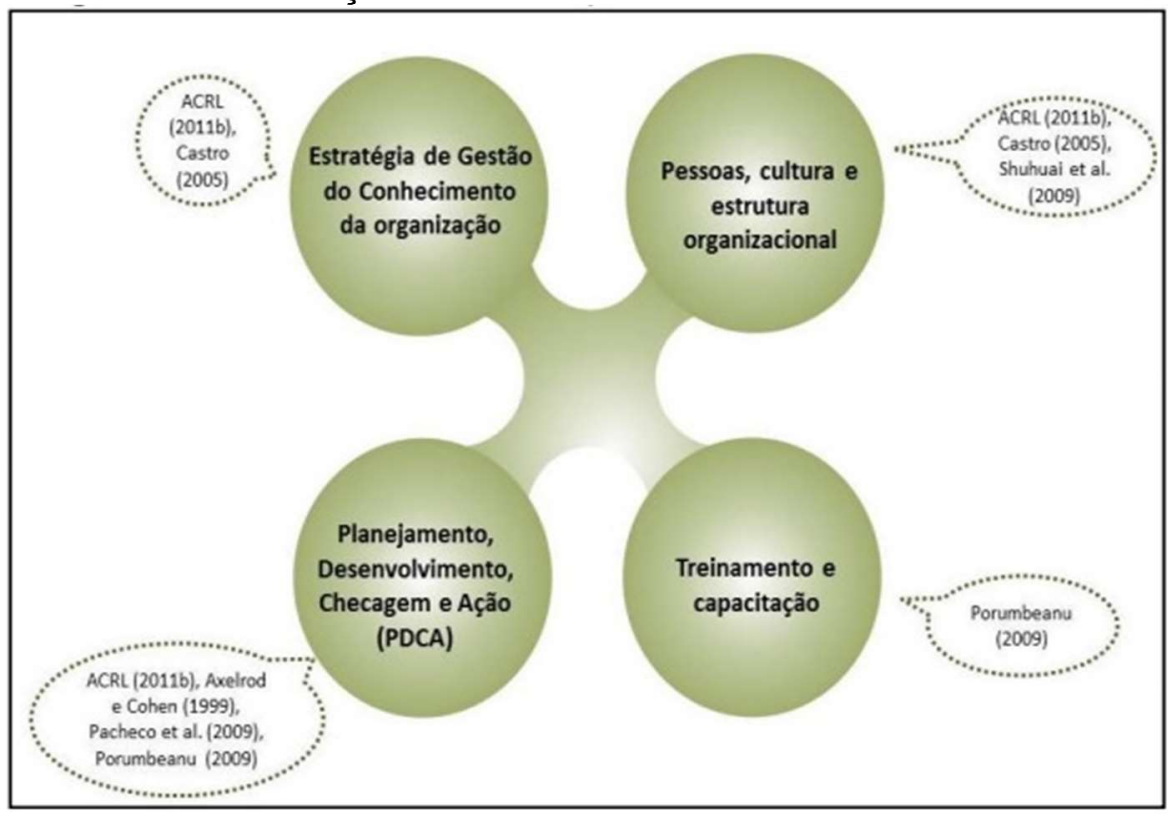

Fonte: Bem (2015) 
Neste artigo trata-se apenas dos elementos "Estratégia de Gestão do Conhecimento da organização; Treinamento e capacitação; e, Planejamento, Desenvolvimento, Checagem e Ação (PDCA)", pois, um artigo sobre o elemento de "Pessoas, cultura e estrutura organizacional" está em vias de publicação.

A equipe que compõe a comissão elaborou um artigo para cada parte da aplicação do Framework GC@BU. Esses artigos estão sendo disponibilizados no site de Gestão do Conhecimento - BU (UNIVERSIDADE FEDERAL DE SANTA CATARINA, 2016d).

\section{APLICAÇÃO DOS ELEMENTOS}

A aplicação dos elementos "Estratégia", "Treinamento e capacitação" e "PDCA", três dos quatro elementos presentes no "Módulo Coordenação de Gestão do Conhecimento", é embasado na planilha do Framework de Bem (2015, p.221, 226-227, 229-231).

O elemento "Estratégia" é composto por seis critérios de verificação, os quais foram analisados, avaliados com sugestões para implementar ações, conforme descrito no Quadro 1.

\begin{tabular}{|c|c|c|}
\hline \multicolumn{3}{|c|}{ Quadro 1 - Aplicação do elemento “Estratégia” } \\
\hline $\begin{array}{l}\text { CRITÉRIOS DE } \\
\text { VERIFICAÇÃOO }\end{array}$ & DIAGNÓSTICO GERAL & AÇÃO \\
\hline $\begin{array}{l}\text { 1. Tem missão, visão, } \\
\text { valores, estratégia } \\
\text { organizacional } \\
\text { planejamento, de forma } \\
\text { bem definida e visível, } \\
\text { compartilhando com } \\
\text { todos e destacando seu } \\
\text { valor para a efetividade } \\
\text { institucional. }\end{array}$ & $\begin{array}{l}\text { Possui, mas os conceitos de missão, visão } \\
\text { e valores estão sendo utilizados de forma } \\
\text { divergente e o planejamento está em fase } \\
\text { de atualização. }\end{array}$ & $\begin{array}{l}\text { Retomar o contato com áreas } \\
\text { de planejamento e e } \\
\text { administração da Universidade } \\
\text { para alinhar as ações } \\
\text { definidas na comissão de GC }\end{array}$ \\
\hline $\begin{array}{l}\text { 2. Possui seus objetivos e } \\
\text { missão alinhados com os } \\
\text { objetivos da universidade } \\
\text { e contribui para o seu } \\
\text { desenvolvimento. }\end{array}$ & $\begin{array}{l}\text { É necessário atualizar e formalizar a missão } \\
\text { e objetivos. }\end{array}$ & $\begin{array}{l}\text { ao Planejamento Estratégico } \\
\text { da BU/UFSC. }\end{array}$ \\
\hline
\end{tabular}


Tatiana Rossi, Wanessa Caroline da Silva, Marli Dias De Souza Pinto, Maria Bernardete Martins Alves, Roberta Moraes de Bem

A gestão do conhecimento sob o ponto de vista de sua coordenação: estratégia, treinamento e planejamento

3. Aloca seus recursos (humanos e financeiros) de forma eficaz para o alcance de seus objetivos e missão.
Embora não se tenha orçamento próprio, é feita a gestão dos recursos destinados à BU/UFSC respaldados nas necessidades da comunidade e realizada a gestão de recursos humanos, sempre que possível, embasado na gestão por competência.
Resgatar a política de
aquisição informacional por percentual para cada centro de ensino; estabelecer diretrizes para afastamento e participação em eventos; e repassar os conhecimentos entre os servidores e palestrantes convidados, por meio de capacitação formalizada na Pró-Reitoria de Desenvolvimento e Gestão de Pessoas, evitando utilizar recursos externos.

A gestão da BU/UFSC está focada na GC, a partir da aplicação do "Framework GC@BU" formalizada pela Portaria $n^{\circ}$ 849/2015/GR, de 25 de maio de 2015 (UNIVERSIDADE FEDERAL DE SANTA CATARINA, 2015).

A comissão de GC da BU/UFSC está trabalhando para a realização das políticas, normas $e$ instrumentos inexistentes na

5. Formula políticas, biblioteca, por meio dos diagnósticos, normas e instruções com proposições de ações, diretrizes e base nos aspectos da divulgação de normas, manuais, entre GC. outros já existentes, como a criação de mapas mentais disponibilizados no site da Gestão do conhecimento - BU (UNIVERSIDADE FEDERAL DE SANTA CATARINA, 2016e).

6. Preocupa-se com os aspectos relativos à divulgação das estratégias/ações da BU, favorecendo a GC.
A comissão de "Comunicação e Marketing" da BU/UFSC, criada em fevereiro de 2016, está trabalhando para melhorar os aspectos de comunicação (UNIVERSIDADE FEDERAL DE SANTA CATARINA, 2016c).
Acompanhar e avaliar a continuidade desta ação.

Manter a divulgação das estratégias e ações ocorridas na BU/UFSC.

Fonte: Adaptado de Bem (2015, p. 221).

Há expectativa na melhoria da avaliação destes critérios, tendo em vista que apenas duas das ações propostas ainda não foram implementadas ou estejam em vias de se concretizar.

Com relação aos cinco critérios de avaliação do elemento "Treinamento e Capacitação" (Quadro 2), obteve-se avaliação boa em quatro critérios e o critério regular já com a ação encaminhada. 
Tatiana Rossi, Wanessa Caroline da Silva, Marli Dias De Souza Pinto, Maria Bernardete Martins Alves, Roberta Moraes de Bem

A gestão do conhecimento sob o ponto de vista de sua coordenação: estratégia, treinamento e planejamento

Quadro 2 - Aplicação do elemento "Treinamento e capacitação"

\begin{tabular}{|c|c|c|}
\hline CRITÉRIOS DE VERIFICAÇÃO & DIAGNÓSTICO GERAL & AÇÃO \\
\hline $\begin{array}{l}\text { 1. Dispõe de métodos adequados } \\
\text { para a introdução da GC de forma } \\
\text { equilibrada (palestras, workshops, } \\
\text { exposições etc.). }\end{array}$ & $\begin{array}{l}\text { A BU/UFSC criou a comissão de } \\
\text { Comunicação e Marketing } \\
\text { especificamente para isso, além } \\
\text { de outras comissões } \\
\text { formalizadas e a retomada do } \\
\text { projeto "Bom dia Biblioteca" } \\
\text { (UNIVERSIDADE FEDERAL DE } \\
\text { SANTA CATARINA, 2016b, c). }\end{array}$ & $\begin{array}{l}\text { Acompanhar e avaliar a } \\
\text { continuidade do projeto e } \\
\text { atividades das comissões. }\end{array}$ \\
\hline $\begin{array}{l}\text { 2. Faz comunicações regulares } \\
\text { para demonstração do andamento } \\
\text { dos projetos de GC, resultados } \\
\text { etc., inclusive para para a a dos aspectos } \\
\text { disseminação dos } \\
\text { relativos à estratégia de GC da } \\
\text { organização e er assuntos } \\
\text { correlatos. }\end{array}$ & $\begin{array}{l}\text { A comunicação é feita por meio } \\
\text { da disponibilização das atas na } \\
\text { íntegra no mural da secretaria } \\
\text { da direção e e o } \\
\text { encaminhamento, por e-mail, } \\
\text { das principais atividades no } \\
\text { boletim "Quais são as novas?". }\end{array}$ & $\begin{array}{l}\text { Acompanhar e avaliar } \\
\text { comunicação interna. }\end{array}$ \\
\hline $\begin{array}{l}\text { 3. Traz colaboradores internos e } \\
\text { externos para corroborar com a } \\
\text { explanação a respeito dos } \\
\text { benefícios e funcionalidades da } \\
\text { GC. }\end{array}$ & $\begin{array}{l}\text { A BU/UFSC possui } \\
\text { representantes externos nas } \\
\text { comissões e a equipe está } \\
\text { avançada com relação a GC. }\end{array}$ & $\begin{array}{l}\text { Manter ativa a GC na } \\
\text { BU/UFSC. }\end{array}$ \\
\hline $\begin{array}{l}\text { 4. Capacita regularmente seus } \\
\text { colaboradores em vários } \\
\text { aspectos. }\end{array}$ & $\begin{array}{l}\text { Os colaboradores realizam } \\
\text { capacitações constantemente, } \\
\text { propiciando a educação } \\
\text { continuada, mas é necessário } \\
\text { viabilizar capacitações } \\
\text { direcionadas e propiciar a vinda } \\
\text { de palestrantes externos sobre } \\
\text { diversas temáticas. }\end{array}$ & $\begin{array}{l}\text { Capacitações direcionadas } \\
\text { aos auxiliares da biblioteca e } \\
\text { bibliotecários serão iniciadas } \\
\text { em setembro de 2016; } \\
\text { propiciar palestras com } \\
\text { profissionais externos à } \\
\text { BU/UFSC de diversas áreas } \\
\text { do conhecimento, como } \\
\text { também apontado no terceiro } \\
\text { critério de verificação do } \\
\text { elemento "Estratégia". }\end{array}$ \\
\hline $\begin{array}{l}\text { 5. Apresenta regularmente as } \\
\text { melhores práticas de GC da } \\
\text { instituição, a fim de motivar e } \\
\text { valorizar as pessoas e seus } \\
\text { trabalhos. }\end{array}$ & $\begin{array}{l}\text { As melhores práticas são } \\
\text { compartilhadas na BU/UFSC } \\
\text { por meio do projeto "Bom dia } \\
\text { Biblioteca" (UNIVERSIDADE } \\
\text { FEDERAL DE } \\
\text { CATARINA, 2016b). }\end{array}$ & $\begin{array}{l}\text { Acompanhar e avaliar } \\
\text { continuidade do projeto. }\end{array}$ \\
\hline
\end{tabular}

Fonte: Adaptado de Bem (2015, p. 226-227).

Observa-se que os critérios de treinamento se relacionam diretamente com os de estratégia de GC, objetivando a capacitação dos conhecimentos específicos dos indivíduos, o compartilhamento e a divulgação das iniciativas e projetos de GC, sempre alinhados às estratégias da BU (BEM, 2015).

O elemento de "Planejamento, Desenvolvimento, Checagem e Ação" (PDCA), também previsto no "Módulo Coordenação e Gestão do Conhecimento" está dividido em 13 critérios de verificação, sendo cinco de 
Tatiana Rossi, Wanessa Caroline da Silva, Marli Dias De Souza Pinto, Maria

Bernardete Martins Alves, Roberta Moraes de Bem

A gestão do conhecimento sob o ponto de vista de sua coordenação: estratégia,

treinamento e planejamento

"Planejamento", dois de "Execução", cinco de "Checagem" e um de "Ação", como pode ser verificado nos Quadros 3, 4 e 5.

Quadro 3 - Aplicação do "Planejamento" do elemento PDCA CRITÉRIOS DE VERIFICAÇÃO

1. Define o que quer com a finalidade de planejar o que será feito. Envolvendo a definição de objetivos, estratégias e ações, os quais devem ser claramente quantificáveis (metas) e quais métodos serão utilizados para se atingir os objetivos traçados.

2. Possui orçamento suficiente para atender às expectativas dos usuários, quando equilibrado com outras necessidades institucionais, sempre resistindo aos esforços e pressões para restringir os recursos da biblioteca.

3. Planeja com base em dados e avaliação de resultados, usando uma variedade de métodos formais e informais.

4. Possui infraestrutura e/ou instrumentos de TIC necessários à coleta, análise e uso dos dados no ciclo PDCA.

5. Registra o conhecimento, levantado na fase de planejamento, por meio do entendimento dos processos e possibilita a transformação do conhecimento tácito em explícito, gerando debates e troca de ideias que proporcionarão troca de conhecimentos, resultando em conhecimentos novos (favorecendo a espiral do conhecimento).

Fonte: Bem (2015, p. 229).

Quadro 4 - Aplicação da "Execução" do elemento PDCA

\begin{tabular}{|c|c|c|}
\hline CRITÉRIOS DE VERIFICAÇÃO & DIAGNÓSTICO GERAL & AÇÃO \\
\hline 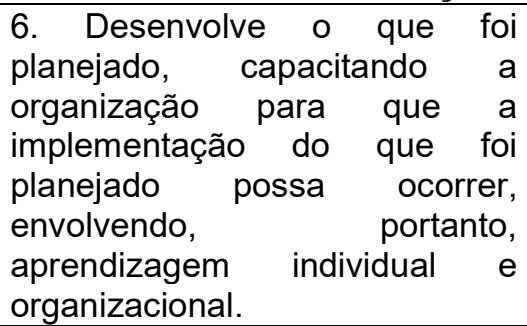 & $\begin{array}{l}\text { Está sendo estabelecido } \\
\text { planejamentos com prazos e } \\
\text { responsáveis, por meio das } \\
\text { comissões de trabalho e } \\
\text { planejamento anual. }\end{array}$ & $\begin{array}{l}\text { A mesma ação do primeiro } \\
\text { critério do elemento } \\
\text { "Estratégia" e também } \\
\text { previstos nos itens um, três, } \\
\text { quatro e cinco do } \\
\text { "Planejamento". }\end{array}$ \\
\hline $\begin{array}{l}\text { 7. Possibilita a socialização e a } \\
\text { combinação do conhecimento } \\
\text { por meio da educação e } \\
\text { capacitação, a interiorização dos } \\
\text { conhecimentos na execução das } \\
\text { tarefas, e o compartilhamento } \\
\text { de conhecimento a respeito do } \\
\text { que foi realizado. }\end{array}$ & $\begin{array}{l}\text { Está sendo finalizado o } \\
\text { mapeamento de processos das } \\
\text { principais atividades realizadas } \\
\text { na BU/UFSC } \\
\text { compartilhamento também ocorre } \\
\text { por meio do projeto "Bom dia } \\
\text { Biblioteca" } \\
\text { FEDERAL (UNIVERSIDADE } \\
\text { CATARINA, 2016b, c). }\end{array}$ & $\begin{array}{l}\text { Compartilhamento, com } \\
\text { todos os servidores da } \\
\text { BU/UFSC, do mapeamento } \\
\text { de processos e fluxogramas } \\
\text { por meio da construção do } \\
\text { manual de Mapeamento de } \\
\text { Processos. }\end{array}$ \\
\hline
\end{tabular}


Tatiana Rossi, Wanessa Caroline da Silva, Marli Dias De Souza Pinto, Maria

Bernardete Martins Alves, Roberta Moraes de Bem

A gestão do conhecimento sob o ponto de vista de sua coordenação: estratégia,

treinamento e planejamento

Fonte: Bem (2015, p. 230).

Quadro 5 - Aplicação da "Checagem" do elemento PDCA

\begin{tabular}{|c|c|c|}
\hline CRITÉRIOS DE VERIFICAÇÃO & DIAGNÓSTICO GERAL & AÇÃO \\
\hline $\begin{array}{l}\text { 8. [...] Comparação dos dados obtidos } \\
\text { na execução com o que foi } \\
\text { estabelecido no plano, com a } \\
\text { finalidade de verificar se os resultados } \\
\text { estão sendo atingidos, conforme o que } \\
\text { foi planejado. }\end{array}$ & $\begin{array}{l}\text { O mesmo diagnóstico do sexto } \\
\text { critério de "Execução". }\end{array}$ & $\begin{array}{l}\text { A mesma ação do } \\
\text { primeiro critério do } \\
\text { elemento "Estratégia", } \\
\text { itens um, três, quatro e } \\
\text { cinco do } \\
\text { "Planejamento" e } \\
\text { sexto da "Execução". }\end{array}$ \\
\hline $\begin{array}{l}\text { 9. Possibilita a transformação do } \\
\text { conhecimento tácito - experiências da } \\
\text { implementação (erros e acertos), } \\
\text { resultado da etapa anterior - em } \\
\text { explícito, gerando novos } \\
\text { conhecimentos, devido à busca pela } \\
\text { resolução dos problemas encontrados. }\end{array}$ & 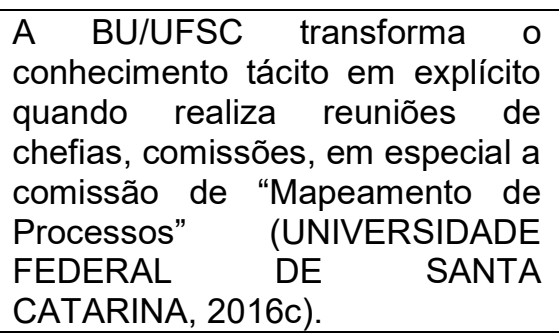 & $\begin{array}{l}\text { Acompanhar e avaliar } \\
\text { a continuidade das } \\
\text { reuniões e atividades } \\
\text { das comissões. }\end{array}$ \\
\hline $\begin{array}{l}\text { 10. Comunica o resultado das } \\
\text { avaliações (checagem) às partes } \\
\text { interessadas. }\end{array}$ & $\begin{array}{l}\text { A BU/UFSC encaminha conforme } \\
\text { demanda. }\end{array}$ & $\begin{array}{lr}\text { A mesma ação } & \text { do } \\
\text { segundo critério } & \text { de } \\
\text { "Treinamento } & \text { e } \\
\text { capacitação". } & \end{array}$ \\
\hline $\begin{array}{l}\text { 11. Apresenta resultados que estejam } \\
\text { alinhados com os assuntos } \\
\text { institucionais, departamentais e } \\
\text { estudantis e com as diretrizes de } \\
\text { credenciamento da instituição e seus } \\
\text { cursos. }\end{array}$ & $\begin{array}{l}\text { A BU/USFC sempre busca } \\
\text { verificar as diretrizes institucionais } \\
\text { e necessidades da comunidade } \\
\text { com: as aquisições visando o } \\
\text { Plano de Ensino; as reuniões } \\
\text { periódicas com a Comissão de } \\
\text { Desenvolvimento de Coleções; o } \\
\text { refinamento do sistema } \\
\text { gerenciador do acervo; entre } \\
\text { outras. }\end{array}$ & $\begin{array}{l}\text { Acompanhar e avaliar } \\
\text { as diretrizes } \\
\text { institucionais. }\end{array}$ \\
\hline $\begin{array}{l}\text { 12. Desenvolve e mantém um conjunto } \\
\text { de evidências (provas, cases de } \\
\text { sucesso etc.) que demonstram o seu } \\
\text { impacto (para a aprendizagem do } \\
\text { aluno, por exemplo) de forma positiva } \\
\text { e convincente, compartilhando } \\
\text { resultados e fazendo melhorias. }\end{array}$ & $\begin{array}{l}\text { A comissão de "Comunicação e } \\
\text { Marketing" está atuando nesse } \\
\text { sentido, porém, é preciso verificar } \\
\text { como a biblioteca pode ter um } \\
\text { maior impacto na comunidade. }\end{array}$ & $\begin{array}{l}\text { Unir e divulgar os } \\
\text { elogios recebidos na } \\
\text { biblioteca por diversos } \\
\text { canais. }\end{array}$ \\
\hline
\end{tabular}

Fonte: $\operatorname{Bem}(2015$, p. 230).

\section{Quadro 6 - Aplicação da "Ação" do elemento PDCA}

\begin{tabular}{|c|c|c|}
\hline $\begin{array}{l}\text { CRITÉRIOS DE } \\
\text { VERIFICAÇÃO }\end{array}$ & DIAGNÓSTICO GERAL & AÇÃO \\
\hline $\begin{array}{l}\text { 13. Age fazendo as correções } \\
\text { necessárias com o intuito de } \\
\text { evitar que a repetição do } \\
\text { problema venha a ocorrer }\end{array}$ & $\begin{array}{l}\text { A BU/UFSC promove debates por meio da } \\
\text { comissão de "Mapeamento de Processos" e em } \\
\text { diversas reuniões propiciando a discussão e } \\
\text { registrando as decisões necessárias em atas. }\end{array}$ & $\begin{array}{l}\text { Manter } \\
\text { debates } \\
\text { registros. }\end{array}$ \\
\hline
\end{tabular}

Fonte: Bem (2015, p. 231).

A avaliação da fase de planejamento do elemento do "PDCA" foi ruim, o que requer as ações previstas para a melhoria destes critérios. Na fase de 
execução, um critério teve avaliação ruim e um critério foi bom, já na fase de checagem, três dos cinco critérios foram avaliados como bons e os outros dois como regulares e, por fim, o critério da fase de ação teve avaliação regular.

Ressalta-se a necessidade da BU estar constantemente atenta aos aspectos negativos e positivos e realizar as modificações necessárias, por isso o planejamento, desenvolvimento, checagem e ação das atividades realizadas em seu âmbito devem ser constantemente avaliados.

Após a aplicação desse elemento, identificou-se que o PDCA poderia ser colocado como o primeiro elemento do Framework, considerando que a aplicação do GC@BU prevê a implementação de ações, e que o PDCA contribuiria no sentido de dispor de um modelo disciplinar para acompanhamento das ações levantadas, a partir do diagnóstico inicial.

O planejamento estratégico, bem como as demais ações que estão pendentes de encaminhamentos serão realizadas durante as próximas reuniões da comissão de GC, por se tratarem de aspectos relevantes para o encaminhamento de outros elementos do Framework GC@BU a serem avaliados.

\section{CONSIDERAÇÕES FINAIS}

O planejamento em qualquer organização consiste em definir o que se almeja, propor diretrizes para realizar ações, estabelecer metas e traçar uma metodologia para atingir os objetivos propostos e isso está sendo direcionado a partir do Framework GC@BU.

Deve-se observar que o treinamento e a capacitação das pessoas são fundamentais para atingir os objetivos, sempre orientados no uso de recursos e no foco das tarefas e atividades a serem realizadas. A proposta da gestão estratégica também deve ser aplicada em bibliotecas universitárias, uma vez que possibilita o aprimoramento dos processos e das atividades vinculadas ao ensino, pesquisa e extensão. 
No estudo realizado na BU houve avanço significativo e os desafios estão sendo impostos. Ressalta-se que as habilidades e conhecimentos são presentes nos bibliotecários e que, com a implementação da GC, a comunicação está em constante melhoria e interação, e tem-se trabalhado com maior espírito de equipe.

A instituição estudada está na esfera da administração pública federal e as $\mathrm{BUs}$, por estarem inseridas nesse contexto, vivenciam um cenário em que o presente estudo, com tal envergadura, constitui-se inovador. Portanto, acreditase que a elaboração dele já seja uma avaliação positiva, pois abre espaços para novas discussões, bem como a sensibilização dos dirigentes responsáveis pelas políticas públicas para o desenvolvimento da educação e motivação, para que outras bibliotecas nacionais implementem a prática de GC.

\section{AGRADECIMENTOS}

À Comissão de GC@BU da UFSC pelas contribuições relevantes na avaliação e diagnóstico dos critérios de verificação do Framework GC@BU.

Agradecimentos extensivos à toda a equipe BU/UFSC.

\section{REFERÊNCIAS}

BEM, R. M.. Framework de Gestão do Conhecimento para bibliotecas universitárias. 2015. 344p. Tese (Doutorado em Engenharia e Gestão do Conhecimento) - Programa de Pós-Graduação em Engenharia e Gestão do Conhecimento, Universidade Federal de Santa Catarina, Florianópolis, 2015. Disponivel em: <http://tede.ufsc.br/teses/PEGC0364-T.pdf>. Acesso em: 26 maio 2016.

CARBONE, P. P. et al. Gestão por competências e gestão do conhecimento. 2. ed. Rio de Janeiro: FGV, 2006.

CARVALHO, A. V.; NASCIMENTO, L. P.; SERAFIM, O. C. G.. Administração de recursos humanos. 2. ed. rev. São Paulo: Cengage Learning, c2012. 
Tatiana Rossi, Wanessa Caroline da Silva, Marli Dias De Souza Pinto, Maria Bernardete Martins Alves, Roberta Moraes de Bem

A gestão do conhecimento sob o ponto de vista de sua coordenação: estratégia, treinamento e planejamento

CASTRO, G. Gestão do conhecimento em bibliotecas universitárias: um instrumento de diagnóstico. 2005. 160 p. Dissertação (Mestrado em Ciência da Informação) - Programa de Pós-Graduação em Ciência da Informação, Universidade Federal de Santa Catarina, Florianópolis, 2005. Disponível em: $<$ https://repositorio.ufsc.br/handle/123456789/101846>. Acesso em: 24 jul. 2016.

CENTENARO, A.; BONEMBERGER, A. M. O.; LAIMER, C. G.. Gestão do conhecimento e vantagem competitiva: estudo no setor metalmecânico $=$ Knowledge management and competitive advantage: study in the metalmechanic sector. Revista de Ciências da Administração, Florianópolis, v. 18, n. 44 , p. 38-51, abr. 2016.

COSTA, L. F.; RAMALHO, F. A. Novas perspectivas dos estudos de satisfação de usuários. Encontros Bibli: Revista Eletrônica de Biblioteconomia e Ciência da Informação, Florianópolis, v. 15, n. 30, p. 57-73, 2010. Disponível em: $<$ https://periodicos.ufsc.br/index.php/eb/article/view/15182924.2010v15n30p57/19530>. Acesso em: 2 jul. 2016.

DALKIR, Z. Knowledge Management in theory and practice. 2nd. Cambridge: MIT Press, 2011.

DANESHGAR, F.; PARIROKH, M. An integrated customer knowledge management framework for academic libraries. The $\mathbf{2 8 1}$ Library Quarterly, v. 82, n. 1, p. 7-28, jan. 2012. Disponível em: $<$ http://web.b.ebscohost.com/ehost/search/basic?sid=f16d28bd-150d-4f3c-bb5f2a958c54a612\%40sessionmgr120\&vid=0\&hid=123>. Acesso em: 17 jul. 2016.

JAIN, P. An empirical study of knowledge management in academic libraries in East and Southern Africa. Library Review, v. 56, n. 5, p. 337-392, 2007. Disponível em: <www.emeraldinsight.com/0024-2535.htm>. Acesso em: 14 abr. 2013.

MARTINS, C. Q. Gestão do conhecimento para serviços de informação: análise de produtos e serviços inovadores em bibliotecas universitárias Biblos: Revista do Instituto de Ciências Humanas e da Informação, Rio Grande, v. 26, n.1, p.930, jan./jun. 2012.

MEDEIROS, R. Educação continuada como parte da formação do profissional: uma ação estruturante. Revista Brasileira de Biblioteconomia e Documentação: Nova Série, São Paulo, v. 2, n. 1, p.105-114, jan./jun. 2006.

MICHEL, K. Design of an intrafirm management development programme for strategic managers. In: ANSOFF, H. I.; DeCLERCK, R.; HAYES,R. (Org.). From strategic planning to strategic management. London: John Wiley \& Sons, 1976. p.152-171. 
Tatiana Rossi, Wanessa Caroline da Silva, Marli Dias De Souza Pinto, Maria Bernardete Martins Alves, Roberta Moraes de Bem

A gestão do conhecimento sob o ponto de vista de sua coordenação: estratégia, treinamento e planejamento

MIRANDA, A. C. D. Bibliotecas universitárias como gestoras do conhecimento em instituições federais de ensino superior: proposta de diretrizes. Florianópolis, 2010. 175f. Tese (Doutorado em Engenharia e Gestão do conhecimento) - Programa de Pós-graduação em Engenharia e Gestão do Conhecimento, Universidade Federal de Santa Catarina, 2010.

MINTZBERGER, H.; QUIN, J. B. O Processo da estratégia. 3. ed. Porto Alegre: Bookmann, 2001.

NICOLAU, I. A gestão do conhecimento como instrumento para a estratégia competitiva. Economia Global e Gestão, Lisboa, v. 2, p. 21-44, 2005.

PACHECO, A. P. R. et al. O ciclo PDCA na gestão do conhecimento: uma abordagem sistêmica. [2005?]. Disponível em: < http://isssbrasil.usp.br/artigos/ana.pdf>. Acesso em: 17 ago. 2016.

PERIARD, G. Ciclo PDCA e a melhoria contínua. 2011. Disponível em: < http://www.sobreadministracao.com/o-ciclo-pdca-deming-e-a-melhoriacontinua/>. Acesso em: 1 jul. 2016.

RIBEIRO, A. L. Gestão de pessoas. São Paulo: Saraiva, 2006.

SHANHONG, T. Knowledge management in libraries in the 21 st century. In: IFLA COUNCIL AND GENERAL CONFERENCE, 66., 2000, Jerusalém, Israel. Anais... Jerusalém, Israel: IFLA, 2000. Disponível em: <https://www.ifla.org/>. Acesso em: 15 jul. 2016.

SANTOS, F. P. O saber-fazer de bibliotecários de referência no desenvolvimento do letramento informacional acadêmico de graduandos. Belo Horizonte, 2015. Dissertação (Mestrado) - Centro Universitário UNA, Instituto de Educação Continuada e Pesquisa. Belo Horizonte, 2015.

UNIVERSIDADE FEDERAL DE SANTA CATARINA. Biblioteca Universitária. Disponível em: <http://portal.bu.ufsc.br/>. Acesso em: 26 jun. 2016a.

UNIVERSIDADE FEDERAL DE SANTA CATARINA. Bom dia Biblioteca.

Disponível em: <http://portal.bu.ufsc.br/servicos/eventos/bom-dia-biblioteca/>. Acesso em: 26 jun. 2016b.

UNIVERSIDADE FEDERAL DE SANTA CATARINA. Comissões de trabalho. Disponível em: <http://portal.bu.ufsc.br/conheca-a-bu/comissoes-de-trabalho/>. Acesso em: 26 jun. 2016c. 
Tatiana Rossi, Wanessa Caroline da Silva, Marli Dias De Souza Pinto, Maria Bernardete Martins Alves, Roberta Moraes de Bem

A gestão do conhecimento sob o ponto de vista de sua coordenação: estratégia, treinamento e planejamento

UNIVERSIDADE FEDERAL DE SANTA CATARINA. Gestão do Conhecimento - BU. Artigos publicados. Disponível em:

<http://gestaodoconhecimento.bu.ufsc.br/artigos-publicados/>. Acesso em: 26 jun. 2016d.

UNIVERSIDADE FEDERAL DE SANTA CATARINA. Gestão do Conhecimento - BU. Mapas mentais. Disponível em:

$<$ http://gestaodoconhecimento.bu.ufsc.br/mapas-mentais/>. Acesso em: 26 jun. 2016 e.

UNIVERSIDADE FEDERAL DE SANTA CATARINA. Portaria $\mathbf{n}^{\circ}$ 849/2015/GR, de 25 de maio de 2015. Florianópolis, 2015.

VALENTIM, M. L.. Gestão da informação e do conhecimento em unidades e serviços de informação. In: CONGRESSO BRASILEIRO DE BIBLIOTECNOMIA E CIÊNCIA DA INFORMAÇÃO, 25, 2013, Florianópolis. [Apresentação...] Florianópolis, 2013.

\title{
Title
}

Management of knowledge in his viewpoint coordination: strategy, training and planning

\begin{abstract}
:
Introduction: It addresses the Knowledge Management in university libraries revealing a scenario involving people, technology and processes and requires the continued preparation of managers, librarians and administrative technician. Objective: To report on the application of the Framework GC@BU, "Knowledge Management Coordination Module" (Strategy element, Training and capacity and PDCA cycle) in the University Library of the Federal University of Santa Catarina. Methodology: The participant observation technique was used, since the researchers analyzed the social reality that surrounds them, and sought to range BU/UFSC strategy to the KM guidelines. Results: It can be seen that challenges are still being established, but significant advances are being made, and the team of librarians begins to participate in training and qualification, aiming at a qualitative work, focused on the maintenance and creation of KM practices. Conclusion: It can be concluded that there was improvement in the communication and interaction of the team.
\end{abstract}

Keywords: Knowledge management. Training. Strategy. PDCA cycle. Framework GC@BU.

\section{Titulo}

Gestión del conocimiento em la coordinación su punto de vista: estrategia, capacitación y planificación 
Tatiana Rossi, Wanessa Caroline da Silva, Marli Dias De Souza Pinto, Maria Bernardete Martins Alves, Roberta Moraes de Bem

A gestão do conhecimento sob o ponto de vista de sua coordenação: estratégia, treinamento e planejamento

\section{Resumen:}

Introducción: Aborda la Gestión del Conocimiento en bibliotecas universitarias revelando un escenario involucrado con personas, tecnologías y procesos e impone la preparación continuada de los gestores, bibliotecarios y técnico-administrativos. Objetivo: Informar a la aplicación del Framework GC@BU, "Módulo Coordinación de Gestión del Conocimiento" (elemento Estrategia, Entrenamiento y capacitación y PDCA) en la Biblioteca Universitaria (BU) de la Universidad Federal de Santa Catarina (UFSC). Metodología: Se utilizó la técnica de observación participante, una vez que los investigadores analizaron la realidad social que los rodea y, buscaron alinear la estrategia de la BU/UFSC a las directrices de la GC. Resultados: Se verifica, qué desafíos todavía están siendo impuestos, pero se perciben avances significativos y el equipo de bibliotecarios, empiezan a participar en entrenamientos y capacitaciones, buscando un trabajo cualitativo, orientado hacia el mantenimiento y la creación de prácticas de GC. Conclusión: Se concluye apuntando que hubo mejoría en la comunicación y en la interacción del equipo.

Palabras clave: Gestión del conocimiento. Entrenamiento. Estrategia. Ciclo PDCA. Marco GC@BU.

Recebido em: 15.02.2017

Aceito em: 13.12.2017 